\title{
Do Brazilian hospital pharmacists record, document, archive and disseminate their clinical practice?
}

\author{
Eugenie Desirèe Rabelo Néri ${ }^{\circledR}$, Hemerson Bruno da Silva Vasconcelos ${ }^{2}$, Geysa Aguiar Romeu \\ Marta Maria de França Fonteles ${ }^{4}$
}

\begin{abstract}
${ }^{I}$ Surveillance and Patient Safety Sector, Assis Chateaubriand Maternity School, Federal University of Ceará, Fortaleza, CE, Brazil, ${ }^{2}$ Planning Sector, Assis Chateaubriand Maternity School, Federal University of Ceará, Fortaleza, CE, Brazil, ${ }^{3}$ Pharmacy Course, University of Fortaleza (UNIFOR), Fortaleza, CE, Brazil, ${ }^{4}$ Postgraduate Program in Pharmaceutical Sciences, Faculty of Pharmacy, Dentistry and Nursing, Federal University of Ceará, Fortaleza, CE, Brazil
\end{abstract}

\begin{abstract}
An exploratory study was conducted to present the approach of Brazilian hospital pharmacists to registering, documenting, archiving and disseminating clinical practice. The data were collected using an electronic questionnaire $(\mathrm{n}=348)$. In fact, $97.41 \%$ of pharmacists record their clinical practice, out of which $64.01 \%(n=217)$ do in electronic form, mainly in private hospitals $(\mathrm{p}<0.000)$, in the central, southern and southeastern regions $(\mathrm{p}=0.040)$, and by professionals with $1-5$ years of experience $(\mathrm{p}=0.001)$. The main software used is non-specific to clinical practice: an electronic spreadsheet $(47.93 \%$; $\mathrm{n}=104)$ and text editor $(13.37 \%$; $n=29)$. The archiving of records is performed by $87.61 \%(\mathrm{n}=297)$ of professionals, where $80.13 \%(\mathrm{n}=238)$ do so in physical form; however, $77.31 \%(\mathrm{n}=184)$ of these files are kept for less than the standard recommended time. Documentation in medical records is carried out by $55.17 \%(\mathrm{n}=192)$ of pharmacists, increasing among those with $1-5$ years of clinical practice $(\mathrm{p}=0.001)$, and dissemination is performed by $74.71 \%(\mathrm{n}=260)$ of hospital pharmacists, with a lower frequency in public hospitals $(\mathrm{p}=0.012)$ and among professionals with fewer hours dedicated exclusively to clinical pharmacy $(\mathrm{p}=0.012)$. These results can undergird the revision of competency-based training programs of Brazilian clinical pharmacists to remain pharmacists as a valuable health team member.
\end{abstract}

Keywords: Pharmacy. Clinical pharmacy services. Pharmacists/study. Brazil.

\section{INTRODUCTION}

Pharmacists' clinical practice in hospitals has had a positive impact on the reduction of hospital stays and mortality, as well as costs from providing benefits to patients and health institutions (Bond, Raehl, 2007). This practice, aimed at clinical management of medications, needs to be supported by a well-developed method, documented and integrated into the care process, in order to maximize the benefits delivered to the patient (Fernandes et al., 2015).

The evaluation of pharmacists' clinical activities and their impact on the quality of patient care is undeniably dependent on the collection of registered

\footnotetext{
*Correspondence: E. D. R. Néri. Maternidade-Escola Assis Chateaubriand, Universidade Federal do Ceará. Rua Coronel Nunes de Melo St. s/n. Rodolfo Teófilo, 60430-270, Fortaleza-Ceará - Brasil. Tel.: (85) 3366-8503 (85) 99133-1788. E-mail: eugenie_neri@yahoo.com
}

data, documented and archived in a structured way that allows retrieval of information for further usage. Without a documentation system, the practice of pharmaceutical care does not exist (Mackinnon III, Mackinnon, 2011; Fernandes et al., 2015).

Nevertheless, the use of medical records to document pharmacists' clinical practice is still not seen as either natural or simple (Pullinger, Franklin, 2010). The pharmacists' actions, such as recording, documenting, archiving and disseminating the data obtained during this practice have an impact on patients', professionals' and institutions' benefits (Nurgat et al., 2011).

Registration can be conceptualized as an act or outcome of recording observations, consigned to writing, to make certain information exists (Ferreira, 2010). Based on this concept, clinical information only exists if presented in writing. However, not every written record documents clinical practice, since the information recorded may have any level of legal or evidential value. 
To document clinical practice, it is necessary to affix records to the patient's medical records chart. The patient's medical records chart is considered a legal, unique, confidential and scientific instrument, where information on patient care should be arranged in an organized, concise and timely manner. The patient's medical records chart serves as a valuable tool for multi-professional communication, decision support, as well as a proof of care, safeguarding the rights of patients and professionals (Brasil, 2002). The documentation of clinical practice is an important method to demonstrate the value of the pharmacist to the organization, and it is also a powerful tool to communicate decisions and share targets to be reached by the patient (Mackinnon III, Mackinnon, 2011).

In the last decade, Brazil has experienced a movement to expand pharmacists' clinical training, both in undergraduate and postgraduate studies. This movement is mainly characterized by the training of pharmacists in multidisciplinary residency programs and in the area of professional health (Sociedade Brasileira de Farmácia Hospitalar e Serviços de Saúde, 2017). In this context, considering the approach of Brazilian hospital pharmacists to registering, documenting, archiving and disseminating clinical practice will allow critically rethinking the currently implemented training in Brazilian pharmacy undergraduate and postgraduate programs, thus creating opportunities to deal with system flaws.

This study was guided by two major questions: 1 . Do Brazilian hospital pharmacists document their clinical practice in medical records and disseminate them? 2. Is the registration, documentation and archiving of this practice carried out using electronic tools and does it comply with Brazilian standards?

\section{METHODS}

An exploratory, qualitative and quantitative study was carried out in Brazil with the participation of clinical pharmacists who work in public and private hospitals. The sample was calculated using the first Brazilian Census of Hospital Pharmacy (Brasil, 2017a) conducted by the Federal Pharmacy Council, which showed that there were 5,489 pharmacists working in hospitals. Considering a $95 \%$ confidence interval $(\mathrm{p}<0.05)$, and that $25 \%$ of hospital pharmacists worked in clinical pharmacy, the minimum sample size $(n=274)$ was determined and stratified into Federative Units according to percentages defined in the Census.

To collect the data, a questionnaire with 26 open- and close-ended questions in Portuguese was prepared for the purpose of this study. The results of 14 questions of the
"Questionnaire on knowledge, skills and approach in the use of information technology (internet and software) to record clinical practice in the daily routine of Brazilian hospital pharmacists" were selected and presented. The following questions were selected: state where the pharmacist works; gender; age group; number of weekly hours dedicated exclusively to the clinical pharmacy; clinical pharmacy experience; type of hospital in which the pharmacist performs clinical pharmacy (public or private); establishment size (number of beds); hospital location (capital city or countryside); clinical activities performed by the pharmacist in the hospital; does the pharmacist use software for recording clinical practice (yes or no); name of the software used; owner of the software used for recording clinical practice (hospital or pharmaceutical); tools the pharmacist uses to prepare reports and documents regarding clinical practice and the time when records are archived.

The questionnaire was validated in advance by a committee of 10 specialists. They were invited to judge the relevance of each question and the clarity of the content of each item, by using "relevance" and "clarity" scales (relevance: 1-irrelevant, 2-somewhat relevant, 3-relevant and 4-very relevant; and clarity: 1-not clear, 2-somewhat clear, 3-clear and 4-very clear) (Polit, Beck, 2006). During validation of the questionnaire, each reviewer voted only once on each question to determine a content validity index (CVI), which measures the proportion or percentage of evaluators who are in agreement regarding certain aspects of the instrument. All questions with CVI (clarity and relevance) equal to or greater than 0.9 were kept in the questionnaire without alteration, and those with CVI less than 0.9 were improved.

After validation, the questionnaire was organized on the Google docs ${ }^{\circledR}$ platform in a way that it allows a single response per participant. After reading and agreeing to an informed consent form, using the participant's Internet Protocol-IP number to block a twofold response, but without identifying the respondents, the participants completed the questionnaire. The questionnaire was sent by e-mail to all selected hospital pharmacists and answered without researchers' assistance. The objectives of the study were widely disseminated in the Group of Clinical Pharmacists on Facebook $^{\circledR}$ and in the groups on the clinical pharmaceutical website (https://farmaceuticoclinico.com.br/). Data collection occurred from July 27 to September 27, 2015.

To ensure that the study objective was achieved, the following were defined as exclusion criteria: a) questionnaires received from pharmacists who declared that they did not work in a hospital; b) questionnaires received from pharmacists who worked in a hospital but declared that they did not carry out clinical activities. 
Data were analyzed using descriptive statistics (frequency, percentage, mean, standard deviation and mode). Pearson's Chi-square test was used for categorical variables and the Gama correlation test was applied to analyze probability distributions. In addition, a likelihood ratio test $\mathrm{G}$ for frequency less than 5 was calculated, using the Assocstats package of $\mathrm{R}$ software (version 3.2.2).

The study was carried out after approval of the Research Ethics Committee of the Federal University of Ceará, CAAE: 44308815.7.0000.5054.

\section{RESULTS AND DISCUSSION}

The survey was completed by 357 hospital pharmacists, although nine questionnaires were discarded because they met the exclusion criteria, resulting in a sample consisting of 348 valid questionnaires. The answers obtained during the validation process of the questionnaire were excluded from the results of this study.

\section{Demographics}

Based on the number of hospital pharmacists defined in the first Brazilian Census of Hospital Pharmacies $(\mathrm{n}=5,489)$ (Brasil, 2017b), and considering that 25\% of them work in a clinical pharmacy $(n=1,373)$, the questionnaire obtained a response rate of $25.34 \%$ $(n=348)$ of hospital pharmacists, with representation of all federative units in Brazil (Table I).

The participants were mostly female $(n=242$; $69.54 \%)$ and between 26 and 40 years old $(n=232$; $66.66 \%$ ), similar to the information evidenced in a study on a profile of Brazilian pharmacists (Serafin, Vargas, 2015). In terms of the practice, hospital pharmacists reported working mainly in public hospitals $(n=260$; $74.71 \%)$, capital hospitals $(n=266 ; 76.44 \%)$, and in hospitals with more than 150 beds $(n=208 ; 59.77 \%)$. These results suggest that a larger number of hospital pharmacists work in the Brazilian public sector rather than in the private sector, since most hospitalization establishments in Brazil (58\%) belong to the private sector, according to the IBGE. The greater number of hospital pharmacists in capitals can be explained by the concentration of $98.08 \%$ of health establishments offering hospitalization being found in Brazilian capitals (IBGE, 2017a).

In terms of clinical practice the majority of pharmacists reported having 1 to 5 years of experience $(\mathrm{n}=185 ; 53.17 \%)$ and between 2 and 24 hours of weekly time exclusively dedicated to clinical pharmacy $(n=201$; $57.76 \%)$, with $25 \%(\mathrm{n}=87)$ of professionals dedicating
TABLE I - Distribution of the answers of the questionnaire by federative unit of Brazil

\begin{tabular}{lcc}
\hline Federative unit of Brazil & $\boldsymbol{f}$ & $\mathbf{\%}$ \\
\hline Acre & 3 & 0.86 \\
Alagoas & 1 & 0.29 \\
Amapá & 3 & 0.86 \\
Amazonas & 5 & 1.44 \\
Bahia & 24 & 6.90 \\
Ceará & 58 & 16.68 \\
Federal District & 6 & 1.72 \\
Espírito Santo & 2 & 0.57 \\
Goiás & 12 & 3.45 \\
Maranhão & 7 & 2.01 \\
Mato Grosso & 3 & 0.86 \\
Mato Grosso do Sul & 4 & 1.15 \\
Minas Gerais & 25 & 7.18 \\
Pará & 2 & 0.57 \\
Paraíba & 1 & 0.29 \\
Paraná & 26 & 7.47 \\
Pernambuco & 6 & 1.72 \\
Piauí & 10 & 2.87 \\
Rio de Janeiro & 19 & 5.46 \\
Rio Grande do Norte & 22 & 6.32 \\
Rio Grande do Sul & 29 & 8.33 \\
Roraima & 1 & 0.29 \\
Rondônia & 3 & 0.86 \\
Santa Catarina & 9 & 2.59 \\
São Paulo & 48 & 13.80 \\
Sergipe & 14 & 4.02 \\
Tocantins & 548 \\
Total & & 1.44 \\
\hline & $\mathbf{1 0 0 . 0 0}$ \\
\hline
\end{tabular}

between 25 and 40 hours exclusively to clinical pharmacy. These findings are possibly related to the increasing stimulus of pharmacists' clinical performance by hospital accreditation programs (Cardoso, Silva, 2016), the increase in the number of places that have residency programs, as well as the recent standardization of the patient safety program in Brazil (Brasil, 2013).

\section{Clinical activities performed by Brazilian hospital pharmacists}

A total of 20 different types of clinical activities (Table II), and on average $8.66 \pm 3.34$ different clinical 
TABLE II - Clinical activities performed by Brazilian hospital pharmacists

\begin{tabular}{|c|c|c|c|c|c|c|c|}
\hline \multirow{2}{*}{$\begin{array}{l}\text { CLINICAL ACTIVITY } \\
(\mathrm{n}=\mathbf{3 4 8})\end{array}$} & \multicolumn{4}{|c|}{ Time experience in clinical pharmacy } & \multirow{2}{*}{$f$} & \multirow{2}{*}{$\%$} & \multirow{2}{*}{$\mathbf{p}^{\mathbf{c}}$} \\
\hline & $<1$ year & 1-5 years & 6-10 years & $>10$ years & & & \\
\hline $\begin{array}{l}\text { A1. Guidance of nursing team regarding } \\
\text { dilution and drug stability }\end{array}$ & 86 & 157 & 27 & 18 & 288 & 82.76 & 0.370 \\
\hline A2. Analysis of drug-drug interactions & 80 & 160 & 22 & 16 & 278 & 79.89 & $0.001^{\mathrm{d}}$ \\
\hline A3. Daily analysis of prescriptions & 81 & 139 & 25 & 20 & 265 & 76.15 & 0.566 \\
\hline $\begin{array}{l}\text { A4. Assessment of prescribed maximum and } \\
\text { minimum doses }\end{array}$ & 76 & 142 & 27 & 16 & 261 & 75.00 & 0.735 \\
\hline $\begin{array}{l}\text { A5. Guidance of medical staff regarding } \\
\text { dilution and drug stability }\end{array}$ & 53 & 131 & 24 & 17 & 225 & 64.65 & $0.010^{\mathrm{d}}$ \\
\hline A6. Analysis of drug-food interactions & 58 & 121 & 16 & 11 & 206 & 59.20 & 0.040 \\
\hline A7. Notification of adverse health events ${ }^{\mathrm{a}}$ & 52 & 110 & 22 & 18 & 202 & 58.05 & 0.136 \\
\hline A8. Pharmacovigilance & 51 & 112 & 22 & 15 & 200 & 57.47 & 0.281 \\
\hline $\begin{array}{l}\text { A 9. Is suing of pharmaceutical } \\
\text { recommendations to health team members }\end{array}$ & 42 & 117 & 19 & 16 & 194 & 55.75 & 0.002 \\
\hline A10. Medication reconciliation & 42 & 116 & 17 & 10 & 185 & 53.16 & $0.002^{\mathrm{d}}$ \\
\hline A11. Multidisciplinary in-hospital visits & 38 & 116 & 17 & 12 & 183 & 52.58 & $<0.000^{\mathrm{d}}$ \\
\hline $\begin{array}{l}\text { A12. Hospital discharge orientation of the } \\
\text { patient }\end{array}$ & 31 & 92 & 12 & 15 & 150 & 43.10 & $0.001^{\mathrm{d}}$ \\
\hline A13.Analysis of medication return & 31 & 58 & 10 & 11 & 110 & 31.61 & 0.457 \\
\hline $\begin{array}{l}\text { A14.Elaboration of patient transfer notes } \\
\text { with the information on pharmaceutical care } \\
\text { provided, and their delivery at the time of } \\
\text { patient transfer, between units of the same } \\
\text { hospital }\end{array}$ & 3 & 14 & 4 & 1 & 22 & 6.32 & 0.252 \\
\hline A15. Multidisciplinary home visits & 0 & 12 & 2 & 3 & 17 & 4.89 & 0.366 \\
\hline $\begin{array}{l}\text { A16. Elaboration of patient transfer notes, } \\
\text { with the information on pharmaceutical care } \\
\text { provided and their delivery, at the time of } \\
\text { patient transfer between hospitals }\end{array}$ & 2 & 4 & 1 & 2 & 9 & 2.59 & 0.327 \\
\hline A17. Pharmaceutical consultations & 2 & 0 & 0 & 0 & 2 & 0.57 & $*$ \\
\hline A18. Elaboration of pharmacotherapeutic plan & 1 & 1 & 0 & 0 & 2 & 0.57 & * \\
\hline A19.Clinical protocol monitoring & 0 & 0 & 0 & 2 & 2 & 0.57 & * \\
\hline $\begin{array}{l}\text { A20. Clarification of patient's doubts during } \\
\text { hospitalization }\end{array}$ & 1 & 1 & 0 & 0 & 2 & 0.57 & $*$ \\
\hline
\end{tabular}

a: Notification of adverse events not related exclusively to medications, such as pressure skin lesion; $b$ : Sepsis protocol and anticoagulation management protocol; c: Pearson's Chi square; d: It increases in the category of 1 to 5 years of practice of clinical pharmacy and decreases in others; *: uncalculated data.

activities per professional, with a mode equal to 7 , were mentioned by the pharmacists.

For the most part, no significant difference was identified in the types of activities performed among pharmacists from different regions of the country; however, it was observed that some activities are performed with an increased frequency among professionals with 1 to 5 years of practice (Activities - Table II: A2; A5; A6, A9; A10; A11 and A12). These findings reflect the recent improvement in the training of professionals for these practices (Sociedade Brasileira de Farmácia Hospitalar e Serviços de Saúde, 2017).

The size of the hospital did not seem to influence the types of activities performed, except for the "analysis 
of drug-drug interactions", which was widely performed in hospitals with a greater number of beds $(p=0.007)$, possibly related to a greater number of professionals available. Other activities also varied according to the type of hospital and were more frequently performed in private hospitals (Activities - Table II: A10, $\mathrm{p}=0.008$; A5, $\mathrm{p}=0.003$; and $\mathrm{A} 1, \mathrm{p}=0.000$ ) and in hospitals located in capitals (pharmacovigilance, $\mathrm{p}=0.014$ ). These activities are minimum standards in the hospital accreditation process (Cardoso, Silva, 2016) and strongly encouraged in private hospitals. The greater performance of pharmacovigilance activities in the capitals certainly reflects the higher number of hospitals located in the capitals of the Brazilian states (IBGE, 2017a).

In general, it was found that the higher number of hours per week dedicated exclusively to clinical pharmacy led to the greater number of activities performed by pharmacists $(p<0.05)$. This confirms the importance of pharmacists' exclusive dedication to clinical activity in order to expand the scope of activities offered to patients and society, with emphasis on activities such as multidisciplinary in-hospital visits, issuing of recommendations to team members, and pharmacovigilance, which are directly related to patient safety.

\section{Recording, documenting, archiving and disseminating information obtained during clinical practice}

Among hospital pharmacists, 97.41\% $(n=339)$ stated that they registered their clinical practice mainly by means of electronic media $(n=217 ; 64.01 \%)$. The use of desktop computer software to record clinical pharmacy activities was more frequent in private health care facilities $(p<0.000)$ in the central, southern and southeastern regions $(\mathrm{p}=0.040)$, performed by pharmacists with 1 to 5 years of practice $(\mathrm{p}=0.001)$. Reports in paper format are used by $35.99 \%(n=122)$ of pharmacists and more frequent in public hospitals $(\mathrm{p}=0.001)$. Both the use of paper formats $(p=0.003)$ and computer-based systems $(p<0.000)$ increase as the time of exclusive dedication to clinical activity expands.

Among pharmacists using computer-based systems to register clinical practice ( $\mathrm{n}=217), 97.78 \%(\mathrm{n}=197)$ used software installed on a hospital computer, while $8.22 \%$ $(n=20)$ used software installed on a private computer, thus revealing a disparity in the availability of technological infrastructure in Brazilian hospitals and daily difficulties faced by professionals.

Pharmacists stated that they use software for clinical practice registration (Table III), mentioning
25 different software programs with a text editor and a spreadsheet at top of the list, both of which are not specific to clinical practice records. This can contribute to poor record standardization, taxonomy issues, difficulties in information sharing and retrieval, and the reduction of patient benefits. Poor standardization was a problem associated with software customization to comply with peculiarities in hospitals in the USA and New Zealand (Al-Jedai, Nurgat, 2017).

TABLE III - Software used by Brazilian hospital pharmacists to record clinical practice

\begin{tabular}{lcc}
\hline Software & $\boldsymbol{F}$ & $\mathbf{\%}$ \\
\hline Excel $^{\circledR}$ & 104 & 47.93 \\
Word ${ }^{\circledR}$ & 29 & 13.37 \\
Tasy $^{\circledR}{ }^{\text {a }}$ & 17 & 7.83 \\
Hospital private system & 16 & 7.37 \\
MV ${ }^{\text {b }}$ & 14 & 6.45 \\
Smart ${ }^{\text {c }}$ & 9 & 4.15 \\
Other software $^{\text {d }}$ & 28 & 12.90 \\
\hline Total & $\mathbf{2 1 7}$ & $\mathbf{1 0 0 . 0 0}$ \\
\hline
\end{tabular}

a: Philips Clinical Informatics software - Sistemas de Informação Ltda $^{\circledR} ;$ b: MV Informática Nordeste Ltda ${ }^{\circledR}$ software; c:Pixeon ${ }^{\circledR}$ software; d: other software from regional developers.

Health management software mentioned by the pharmacists reveals the market share of the Brazilian hospital software market (Valor Econômico, 2017), presenting the Philips ${ }^{\circledR}, M V \AA$ and Pixeon ${ }^{\circledR}$ solutions as the most frequently used, along with software customized by the hospitals. These findings associated with the high number of different software identified, such as software possibly customized for each institution (local or regional coverage) mentioned by the pharmacists, confirm that the market is characterized by an abundance of solutions (IBGE, 2017b), making it even more difficult to standardize the process of practice registration and comparing the obtained results to assess the contribution (Al-Jedai, Nurgat, 2017).

The documentation of clinical practice in medical records is performed by $55.17 \%(\mathrm{n}=192)$ of hospital pharmacists with clinical activities in Brazil $(n=348)$, with higher numbers among pharmacists with 1 to 5 years of clinical experience, though the numbers drop with the increase of practice time $(\mathrm{p}=0.001)$. The documentation practice seems to be related to the recent expansion of clinical pharmacist training in Brazil and was reported mainly by pharmacists of the central, southern and southeastern regions $(p=0.001)$, in hospitals with the 
largest number of beds ( $>150$ beds $)(p=0.031)$; its frequency increased among pharmacists with more time dedicated exclusively to clinical pharmacy $(p<0.000)$.

These findings prompt us to reflect to what extent the lack of documentation of pharmacists' clinical practice in medical record charts impact medical care, secure communication, visibility of pharmacists' actions, and legality (Brasil, 2010), and that there is a need for greater emphasis during academic and postgraduate training on how to carry out the documentation of clinical practice, demystifying it and empowering pharmacists to better use the information. The appropriate documentation process allows pharmacists to share their clinical observations with other team members, contributing to adequate information flow in the patient care process and to improve the quality of patient care (Mackinnon III, Mackinnon, 2011).

Pullinger and Franklin (2010) observed a similar situation of low adherence to the documentation of practice in medical records among British pharmacists, detecting the fear of professional conflict, legal proceedings, and the feeling of uncertainty on the part of a pharmacist as to whether he had the right to register recommendations in a medical record. In Brazil, the Federal Pharmacy Council has been encouraging clinical practice and its documentation by promoting actions focused on critical rethinking of the professional education process that will deeply transform this field of knowledge (Brasil, 2017b). Additional research will be needed to identify the reasons why a significant number of Brazilian pharmacists do not document clinical practice, even though it registers it.

The archiving of information generated during pharmacists' clinical practice can be done in traditional files (paper form) or in electronic media (software, microfilming or digitization). In both cases, confidentiality of the information needs to be preserved, as well as its integrity. In Brazil, the archiving of documents produced during pharmaceutical care, including the documents obtained during clinical practice, is regulated by the Federal Council of Pharmacy, which recommends the adoption of electronic means, preferably for recording, document keeping and handling of information obtained during the practice (Brasil, 2008).

In this study, it was established that the clinical practice information was archived by $87.61 \%(\mathrm{n}=297)$ of the pharmacists, out of whom $80.13 \%(\mathrm{n}=238)$ realized it in a physical medium and $19.87 \%(\mathrm{n}=59)$ electronically. Among the pharmacists who perform archiving in a physical medium, $66.38 \%(\mathrm{n}=158)$ kept physical files (on paper), despite electronic registration. This number suggests the use of paper forms to collect data and the lack of data collection devices (e.g., tablets) that can be handled by pharmacists at bedside. The use of these data collection devices is important to avoid using paper. The use of electronic means to archive the information of pharmaceutical practice allows information sharing, facilitates the accessibility of information, guarantees legibility and greater security due to the possibility of information back-up (Braúna, Freitas, 2017). The lack of records for clinical practice reported by $12.39 \%(n=42)$ of pharmacists is in conflict with current regulations (Brasil, 2008), pointing to a system flaw that has to be addressed.

The reported archiving time varied as shown in Table IV, revealing that most pharmacists maintain a physical archive for less than the regulatory minimum period of five years (Brasil, 2008).

TABLE IV - Physical archiving time of instruments used in clinical activities by Brazilian hospital pharmacists

\begin{tabular}{lcc}
\hline $\begin{array}{l}\text { Physical archiving time of } \\
\text { instruments used in clinical } \\
\text { activities (in years) }\end{array}$ & $\mathbf{N}$ & $\mathbf{\%}$ \\
\hline Up to 1 year & 49 & 20.59 \\
1 - 2 years & 54 & 22.69 \\
2 -5 years & 81 & 34.03 \\
5 F 10 years & 19 & 7.98 \\
$\geq 10$ years & 35 & 14.71 \\
\hline Total & $\mathbf{2 3 8}$ & $\mathbf{1 0 0 . 0 0}$ \\
\hline
\end{tabular}

The dissemination of clinical activity through publication of scientific papers or the issuing of reports was reported by $74.71 \%(n=260)$ of the hospital pharmacists, using different electronic tools for their preparation. These findings corroborate the results obtained by Serafin and Vargas (2015), which include hospital pharmacists in the group of pharmacists who publish the most. Among pharmacists who record their clinical practice $(n=339)$, $23.30 \%(n=79)$ still do not disseminate it.

Failure to produce publications and clinical pharmacy reports was mainly reported by pharmacists who work in public hospitals $(\mathrm{p}=0.012)$ and among those with fewer hours dedicated exclusively to clinical pharmacy $(\mathrm{p}=0.012)$.

There are limitations in this study associated with the exclusively electronic availability of the questionnaire through a Google ${ }^{\circledR}$ form, which may have restricted the participation of some professionals. In spite of these limitations, we believe that the biases were minimized by the wide distribution of the questionnaire reflected in the participation of hospital pharmacists from all the federative units of Brazil. 


\section{CONCLUSION}

This study mapped out opportunities for improvement in recording, documenting, archiving and disseminating processes of Brazilian hospital pharmacists' clinical practice, providing valuable assistance to the revision of undergraduate training, as well as to the planning of postgraduate educational activities and activities of continuing education for these health professionals. The adoption of effective strategies for carrying out the documentation of clinical practice in medical records charts is strategic to maintaining the hospital pharmacists as an active and valuable health team member.

In the future, it is important to investigate the factors that limit documentation of the actions of Brazilian hospital pharmacists in medical records, as well as the means used to record these practices. For that, other studies must be conducted in Brazil.

\section{SOURCES OF FUNDING}

This research did not receive any specific grant from funding agencies in the public, commercial, or not-forprofit sectors.

\section{ACKNOWLEDGMENTS}

We thank all the pharmacists who participated in this study and the Federal Council of Pharmacy, Regional Pharmacy Councils and SBRAFH for support.

\section{CONFLICT OF INTEREST}

None.

\section{REFERENCES}

Al-Jedai A, Nurgat ZA. Electronic documentation of clinical pharmacy interventions in hospitals. OnTech Open Science. 2017. Cap. 7. p. 159-178. [cited 2017 Jul 31]. dx.doi.org/10.5772/50425. [internet] Available in: http://cdn. intechopen.com/pdfs/38582/intech-electronic_documentation of_clinical_pharmacy_interventions_in_hospitals.pdf.

Bond CA, Raehl CL. Clinical pharmacy services, pharmacy staffing, and hospital mortality rates. Pharmacotherapy, 2007;27(4):481-93.
Brasil. Conselho Federal de Medicina, Resolução No 1638/2002. Define prontuário médico e torna obrigatória a criação da Comissão de Revisão de Prontuários nas instituições de saúde. Diário Oficial da União. Seção I, p.184-5. 9 de Ago. 2002.

Brasil. Conselho Federal de Farmácia. Resolução n ${ }^{\circ}$ 476, de 28 de maio de 2008. Regulamenta o registro, a guarda e o manuseio de informações resultantes da prática da assistência farmacêutica nos serviços de saúde. Diário Oficial da União, Seção 1, № 103, p.113. Brasília. 02 jun. 2008.

Brasil. Ministério da Saúde. Portaria Gabinete do Ministro $\mathrm{n}^{\circ} 4.283$, de 30 de dezembro de 2010. Aprova as diretrizes e estratégias para organização, fortalecimento e aprimoramento das ações e serviços de farmácia no âmbito dos hospitais. Diário Oficial da União,Seção 1 № 251, p.94-95. Brasília. 31 dez. 2010.

Brasil. Ministério da Saúde. Resolução no 36, de 25 de julho de 2013. Institui ações para a segurança do paciente em serviços de saúde e dá outras providências. Diário Oficial da União,Seção 1 No 143. Brasília, 2013.

Brasil. Conselho Federal de Farmácia, Sociedade Brasileira de Farmácia Hospitalar e Serviços de Saúde. $1^{\circ}$ Consenso Brasileiro de Farmácia Hospitalar [Internet]. [São Paulo-Brasil]: [SBRAFH]; 2010 [cited 2014 Nov 18]. 6 p. Available in: http:// www.sbrafh.org.br/site/public/temp/4f7baaa67ea6f.pdf. Access: 02 Set. $2017 \mathrm{a}$.

Brasil. Conselho Federal de Farmácia. Competências para a atuação clínica do farmacêutico: relatório do I Encontro de Educadores em Farmácia Clínica e matriz de competências para atuação clínica. 124p.:il. Brasília, 2017b.

Braúna CC, Freitas RM. Revisão integrativa sobre o uso de sistemas informatizados na prática da atenção farmacêutica. Revista Eletrônica de Farmácia. 2014;11(1):35-47.

Cardoso CAR, Silva LC. A importância da qualidade na farmácia hospitalar e seu papel no processo de acreditação hospitalar [internet]. Rev Cient UMC Mogi das Cruzes. 2016;1(1):1-15.

Fernandes O, Toombs K, Pereira T, Lyder C, Bjelajac Mejia A, Shalansky S, Al-Sukhni M, Gerdes S, Sohal S, Gorman S. Canadian Consensus on Clinical Pharmacy Key Performance Indicators: Quick Reference Guide. Canadian Society of Hospital Pharmacists. Ottawa, Ontario; 2015.

Ferreira ABH. Mini Dicionário da lingua portuguesa, 8.ed. Curitiba: Positivo; 2010. p. 651. 
IBGE Estatísticas da saúde e Assistência médico-sanitária 2010. RJ. Available in: http://www.ibge.gov.br/home/estatistica/ populacao/condicaodevida/ams/2009/default.shtm. Access: 26 Jun. 2017a.

IBGE. Serviços de Tecnologia 2009. Available in: http:// biblioteca.ibge.gov.br/visualizacao/livros/liv49099.pdf. Access: 24 Fev. $2017 b$.

Mackinnon III GE, Mackinnon NJ. Documentation of Pharmacy Services. Chap.7 In: DiPiro JT, Talbert RL, Yee GC, Matzke GR, Wells BG, Posey LM. Pharmacotherapy: A pathophysiologic approach. [S.1.]: McGraw-Hill; 2011.

Nurgat ZA, Al-Jazairi AS, Abu-Shraie N, Al-Jedai A. Documenting clinical pharmacist. Intervention before and after the introduction of a web-based tool. Int J Clin Pham. 2011;33(2):200-7.

Polit DF, Beck CT. The content validity index: are you sure you know what's being reported? Critique and recomendations. Res Nurs Health. 2006;29(5):489-97.
Pullinger W, Franklin BD. Pharmacists' documentation in patients' hospital health records: issues and educational implications. Int J Pharm Pract. 2010;18(2):108-115.

Serafin C, Vargas M. Perfil do farmacêutico no Brasil: relatório. Brasília: Conselho Federal de Farmácia; 2015. 44 p.

Sociedade Brasileira de Farmácia Hospítalar e Serviços de Saúde. Programa PaRes: padrões para residências farmacêuticas em hospitais e demais Serviços de Saúde. 2.ed. São Paulo: SBRAFH; 2017. 58p.

Valor Econômico. Segmento pode gerar R\$ 1Bi neste ano. [internet]. São Paulo: Jornal Valor Econômico. [atualizado em 22 Nov. 2013]. Disponível em: <http://www.valor.com. br/empresas/3347390/segmento-pode-gerar-r-1-bi-neste-ano> Access: 14 Fev. 2017.

Received for publication on $30^{\text {th }}$ September 2017 Accepted for publication on $12^{\text {th }}$ June 2018 